\title{
Mycoflora Detected from Seeds of Sesamum indicum L. in Sialkot, Pakistan
}

\author{
Brian Gagosh Nayyar ${ }^{*}$, Abida Akram, Muhammad Arshad, S. M. Mughal ${ }^{1}$, \\ Shaista Akhund and Saira Mushtaq ${ }^{2}$ \\ Department of Botany, Pir Mehr Ali Shah Arid Agriculture University, Rawalpindi, 4600 Pakistan \\ ${ }^{I}$ Department of Plant Pathology, Pir Mehr Ali Shah Arid Agriculture University, Rawalpindi, 4600 Pakistan \\ ${ }^{2}$ Department of Biology, Pir Mehr Ali Shah Arid Agriculture University, Rawalpindi, 4600 Pakistan
}

\begin{abstract}
Sesame seeds (Sesamum indicum L.) from various localities of Sialkot were analysed for their mycoflora by using Agar plate, Blotter paper and Deep freezing method. Agar plate and Deep freezing method yielded 22 and 21 fungal species respectively followed by Blotter paper method yielded 19 species. A total number of 36 species belonging to 10 genera of fungi were isolated. The prevalent genera were Penicillium (10 species), Alternaria (7 species), Fusarium (5 species), Cercospora and Cladosporium (4 species each). Penicillium was predominant followed by Alternaria and Fusarium. All detected fungi are the first record of mycolflora from sesame seeds in Sialkot, Pakistan.
\end{abstract}

Key words: Sesamum indicum, seed-borne, Agar plate, Blotter paper, Deep freezing method

\section{Introduction}

Sesame (Sesamum indicum L.) or "til" is one of the world's oldest spice and oilseed crop. It was originated in Africa and is considered to be one of the primeval oil seed plant brought into cultivation in various parts of the world. Presently, China, India, and Myanmar are the leading producers of sesame, followed by Sudan, Nigeria, Pakistan, Bangladesh, Ethiopia, Thailand, Turkey, and Mexico (15). The world production is anticipated at 3.66 million tones with Asia and Africa producing 2.55 and 0.95 million tons, respectively (5). In Pakistan, sesame seeds were refined on over 100,000 hectares of territory during 2001-2002. Entire production that year was 50.7 thousand tones (18). Over 90 per cent of Pakistan's production is exported. Substantial progress in sesame production for the period 2001-2002 is worth mentioning because of the phenomenal growth of 37.2 per cent and Pakistan earned about US\$ 20 million from exports. Of the total sesame production of Pakistan, Punjab contributes 88.5 per cent followed by Balochistan 6.9 per cent, Sindh 4.3 per cent and Khyber Pakhtun Khwa only 0.3 per cent. Gujrat, Sialkot, Bahawalpur, Bhakkar, Chichawatni and Layyah are the main sesame seed growing areas in Punjab (6).

Sesame seeds are prosperous source of protein $(20 \%)$ and edible oil $(50 \%)$, and contain about $47 \%$ oleic acid and 39\% linolenic acid (35). Seeds having shells are loaded with calcium (1.3\%) and adequate mineral supply. Sesame seeds are added to lysine rich soybean meal to make appropriate animal feed (19). They are used as ingredients in manufacturing of bread, candies, chips and health foods whereas Sesame oil is used as cuisine oil, it has brilliant permanence due to the presence of innate antioxidants sesamol, sesamoline and sesamin hence known as the "king of oils" (27). It is also used in cooking, salad preparation, margarine, and raw materials for the manufacturing of paints, varnishes, soaps, perfumes, pharmaceuticals, and insecticides.

Although sesame is extensively used for numerous purposes, the crop has very low yielding capacity as compared to other plants due to various factors specially disease susceptibility (7). Numerous deteriorative microbes particularly fungi have created so many problems in production and storage conditions. Many authors reported the incidence of $A$. flavus in sesame seeds along with other fungi $(21,22)$. These fungi secrete toxic secondary metabolites, out of them Aflatoxin is the most important (2). Other fungi viz., Aspergillus niger, A. viridus, A. alba, Fusarium sp., Alternaria redicina, A. brassicola, Drechslera sp., Curvularia sp., Cephalosporium sp., Penicillium sp. have also been isolated from sesame (4) which have hazardous effects on this crop. Due to which, sesame agriculture is facing numerous problems like root rot, wilting disease, and damping off for seedlings, which is caused by transfer of fungi from soil to plant and thus effect the crop (16).

Revealing seed borne pathogen is a main factor in production and quality to ensure health and vitality. Thus, proper identification of these pathogens is a primary step in planning management. The present work was planned to study the mycoflora of Sesame seeds of Sialkot which is the major growing area of sesame in Punjab. No previous report on seed borne mycoflora of sesame from this region is found. 


\section{Collection of seed samples}

\section{Materials And Methods}

Fifteen seed samples of Sesame were collected from various localities of the Sialkot, Punjab and were preserved in plastic bags and stored in refrigerator until used. For sterilization, seeds were treated with $2 \%$ sodium hypochlorite $(\mathrm{NaOCl})$ for 2 minutes and were rinsed three times with distilled water to remove sanitizing particles. Four hundred seeds were used for each experiment.

\section{Detection of Seed Mycoflora}

Standard blotter, agar plate and deep freezing methods were used for the detection of seed borne fungi as recommended by International Seed Testing Association (17). For agar plate method, the untreated seeds and seeds treated with $2 \% \mathrm{NaOCl}$ were placed on potato dextrose agar (PDA) at the rate of 25 seeds per plate. For blotter and deep freezing methods, the treated and untreated seeds were placed on three layers of moistened blotters placed in Petri plates at the rate of 25 seeds per plate. Then the plates were incubated at $25 \pm 1{ }^{\circ} \mathrm{C}$ for seven days except in deep freezing method in which the plates were incubated for 24 hours at $25 \pm 1{ }^{\circ} \mathrm{C}$ and then transferred to $-20^{\circ} \mathrm{C}$ in a freezer for 24 hours followed by incubation at $25 \pm 1^{\circ} \mathrm{C}$ for 7 days. After incubation period, the number of infested seeds and fungal colonies developed were recorded in term of percentage frequency. Based on macroscopic and microscopic observations, the fungal flora was identified after the reference of Thom and Raper (38), Ellis (13, 14), Domsch et al., (12).

\section{Results}

The occurrence of fungi most frequently encountered is recorded in terms of mean value with standard error (Table 1).

\section{a) Agar Plate Method}

A total of 22 species belonging to nine genera viz. Alternaria alternata, Al. chlamydospora, A. flavus, A. niger, Cercospora sp., C. chenopodii, C. koepkei, Cladosporium variable, C. herbarium, C. tenuissimum, Curvularia richardiae, Dreschlera hawaiinses, Fusarium oxysporum, F. redolens, F. reticulatum, F. tabacinum, Penicillium egyptiacum, $P$. herqui, $P$. janthinellum, P. lanso-coerellum, $P$. paxilli, $R$. oryzae were detected from both surface sterilized and unsterilized seeds with almost same number of colonies and species diversity. Of the fungi isolated $P$. lanso-coerellum, $R$. oryzae, $C$. koepkei and $F$. oxysporum were few predominant species.

\section{b) Blotter Paper Method}

A total of 19 species belonging to eight genera viz. Alternaria alternata, Al. cinerariae, Al. citri, A. flavus, A. niger, Cercospora sp., C. bolleana, C. chenopodii, C. koepkei, C. herbarium, C. sphaerospurmum, Fusarium oxysporum, F. proliferatum, Penicillium egyptiacum, $P$. janthinellum, P. lilacinum, $P$. waksmani, $R$. oryzae, Verticillium albo-atrum were detected from both surface sterilized and unsterilized seeds. The most prevalent fungi were Cercospora sp. and P. egyptiacum. Unsterilized seeds yielded more number of colonies and species.

\section{c) Deep Freezing Method}

A total of 21 species belonging to six genera Alternaria alternata, Al. chlamydospora, Al. cinerariae, Al. citri, Al. pluriseptata, Al. radeina, Al. triticina, A. flavus, A. niger, Cercospora sp., C. herbarium, C. sphaerospurmum, Fusarium oxysporum, F. proliferatum, F. reticulatum, F. tabacinum, Penicillium egyptiacum, $P$. expansum, $P$. italicum, $P$. vermiculatum, $P$. waksmani, were detected from both surface sterilized and unsterilized seeds. Al. chlamydospora, Al. cinerariae, Al. radeina and Cercospora sp. were few predominant species. Here also unsterilized seeds yielded more number of species as compared to sterilized seeds. 
Table 1: Percent frequency of fungi in Agar plate, Blotter paper and Deep freezing method

\begin{tabular}{|c|c|c|c|c|c|c|c|}
\hline \multirow{3}{*}{$\begin{array}{l}\text { S. } \\
\text { No. }\end{array}$} & \multirow{3}{*}{ NAME OF FUNGI } & \multicolumn{2}{|c|}{ AGAR PLATE METHOD } & \multicolumn{2}{|c|}{ BLOTTER PAPER METHOD } & \multicolumn{2}{|c|}{ DEEP FREEZING METHOD } \\
\hline & & S.D* & S.N.D** & S.D* & S.N.D** & S.D* & S.N.D D $^{* *}$ \\
\hline & & Mean \pm S.E & Mean \pm S.E & Mean \pm S.E & Mean \pm S.E & Mean \pm S.E & Mean \pm S.E \\
\hline 1 & Alternaria alternata $(\mathrm{Fr}$.) Keissl. & $5.5 \pm 1.78$ & $7.7 \pm 0.86$ & $33.9 \pm 2.25$ & $28.5 \pm 0$ & $19.7 \pm 2.67$ & $22.4 \pm 3.14$ \\
\hline 2 & Alternaria chlamydospora Mouchacca & $9.3 \pm 0.20$ & $20.1 \pm 0$ & & & $30 \pm 0$ & \\
\hline 3 & Alternaria cinerariae Hor \& Enjoji & & & $6 \pm 0$ & & $34 \pm 0$ & $23 \pm 0$ \\
\hline 4 & Alternaria citri Ellis \& Pierce & & & $38.5 \pm 0$ & & $17.5 \pm 0$ & \\
\hline 5 & Alternaria pluriseptata Karst. \& Har. & & & & & $20 \pm 0$ & $16 \pm 0$ \\
\hline 6 & Alternaria radicina Meier. & & & & & $34 \pm 0$ & $26.4 \pm 0$ \\
\hline 7 & Alternaria triticina Prasada \& Prabhu & & & & & & $20.3 \pm 0$ \\
\hline 8 & Aspergillusflavus Link ex Gray & $14.3 \pm 0$ & $26.5 \pm 0.80$ & & $34.1 \pm 0$ & & $3.4 \pm 0$ \\
\hline 9 & Aspergillus niger Van Tieghem & $10 \pm 0$ & $14.8 \pm 4.37$ & & $20.1 \pm 0$ & & $40 \pm 0$ \\
\hline 10 & Cercospora spp. & $21.3 \pm 1.36$ & $17 \pm 1.64$ & $21.9 \pm 2.76$ & $23.1 \pm 2.47$ & $33 \pm 0.36$ & $18.4 \pm 3.64$ \\
\hline 11 & Cercospora bolleana Thüm. & & & & $3.9 \pm 0$ & & \\
\hline 12 & Cercosporachenopodii Fresen. & $1.8 \pm 0$ & $8.8 \pm 0$ & & $27.8 \pm 0$ & & \\
\hline 13 & Cercospora koepkei Krüger & $27.5 \pm 0$ & & & $33.4 \pm 0$ & & \\
\hline 14 & Cladosporiumvariable Cooke & $22.2 \pm 0$ & & & & & \\
\hline 15 & Cladosporium herbarum(Pers.) Link, Fr. & & $11 \pm 0$ & & $4.9 \pm 0$ & & $2.5 \pm 0$ \\
\hline
\end{tabular}

${ }^{*}$ S.D $=$ Surface disinfected

** S.N.D $=$ Surface non disinfected

Table 1 (Cont'd.)

\begin{tabular}{|c|c|c|c|c|c|c|c|}
\hline \multirow{3}{*}{$\begin{array}{l}\text { S. } \\
\text { No. }\end{array}$} & \multirow{3}{*}{ NAME OF FUNGI } & \multicolumn{2}{|c|}{ AGAR PLATE METHOD } & \multicolumn{2}{|c|}{ BLOTTER PAPER METHOD } & \multicolumn{2}{|c|}{ DEEP FREEZING METHOD } \\
\hline & & S.D* & S.N.D** & $\mathrm{S} . \mathrm{D}^{*}$ & S.N.D $D^{* *}$ & $\mathrm{~S} . \mathrm{D}^{*}$ & S.N.D** \\
\hline & & Mean \pm S.E & Mean \pm S.E & Mean \pm S.E & Mean \pm S.E & Mean \pm S.E & Mean \pm S.E \\
\hline 16 & Cladosporium sphaerospurmum Penz. & & & & $9.8 \pm 0$ & & $11.5 \pm 0$ \\
\hline 17 & Cladosporium tenuissimum Cooke & $10 \pm 0$ & $14.4 \pm 0$ & & & & \\
\hline 18 & Curvularia richardiae Alcom & & $6.9 \pm 0$ & & & & \\
\hline 19 & Drechslera hawaiinses (Bugn.) Sub. Jain & $11 \pm 0$ & & & & & \\
\hline 20 & Fusarium oxysporum Schlecht. & $22.5 \pm 2.93$ & $15.9 \pm 3.2$ & $24.3 \pm 1.19$ & $24.5 \pm 1.0$ & $13.8 \pm 1.36$ & $32.1 \pm 0.43$ \\
\hline 21 & Fusarium proliferatum (Mats.) Nirenberg & & & $20.1 \pm 3.2$ & & $16 \pm 1.46$ & $29.3 \pm 0.37$ \\
\hline 22 & Fusarium redolens Wollenw. & & $15.7 \pm 3.3$ & & & & \\
\hline 23 & Fusarium reticulatum Mont. & & $17.6 \pm 0$ & & & $10.5 \pm 0$ & \\
\hline 24 & Fusarium tabacinum App. \& Wr. & & $22.3 \pm 0$ & & & $30 \pm 0$ & $25 \pm 0$ \\
\hline 25 & Penicilliumegyptiacum (Beyma)Palmet al. & $9.8 \pm 1.78$ & $17.3 \pm 2.42$ & $33 \pm 2.92$ & $50 \pm 1.04$ & $33 \pm 2.92$ & $9.2 \pm 0.60$ \\
\hline 26 & Penicilliumexpansum Link. & & & & & $25 \pm 0$ & $7.5 \pm 0$ \\
\hline 27 & Penicillium herqui Bainier \& Sartory & $11.8 \pm 0$ & & & & & \\
\hline 28 & Penicillium italicum Wehmer & & & & & & $5 \pm 0$ \\
\hline 29 & Penicilliumjanthinellum Biourge & $17.5 \pm 0$ & $13 \pm 0$ & $24 \pm 0$ & & & \\
\hline 30 & Penicillium lanso-coerellum Thom & $36 \pm 0$ & $6.5 \pm 0$ & & & & \\
\hline 31 & Penicillium lilacinum Thom & & & $8 \pm 0$ & & & \\
\hline 32 & Penicillium paxilli Bainier & $5.8 \pm 0$ & $3.2 \pm 0$ & & & & \\
\hline 33 & Penicilliumvermiculatum Dangeard & & & & & & $27.5 \pm 0$ \\
\hline 34 & Penicilliumwaksmani Zaleski & & & $4 \pm 0.36$ & $2 \pm 0$ & & $9.3 \pm 0.60$ \\
\hline 35 & Rhizopus oryzyae Went \& Geerl. & $32.5 \pm 0$ & $30.8 \pm 1.1$ & & $27.8 \pm 0$ & & \\
\hline 36 & Verticillium albo-atrum Reinke \& Berth. & & & $22.4 \pm 0$ & & & \\
\hline
\end{tabular}

\section{Discussion}

Overall in this study Agar plate and Deep freezing method yielded more number of fungi than blotter method but in deep freezing method infection rate was the lowest (Fig.1). Blotter paper method showed moderate rate of infection and found to be suitable for isolation of Cercospora sp. Panchal and Dhale (26) reported that isolation of seed borne fungi by Agar plate method was more favourable than blotter paper method for the maximum counts of saprophytic fungi and for detection of some specific fungi. Such similar results were also observed by Kassim (20) on sorghum, Bilgrami and Ghaffar (9) on pinus, Perveen and Ghaffar (28) on tomato and Rathod et al., (31) on legume seeds.

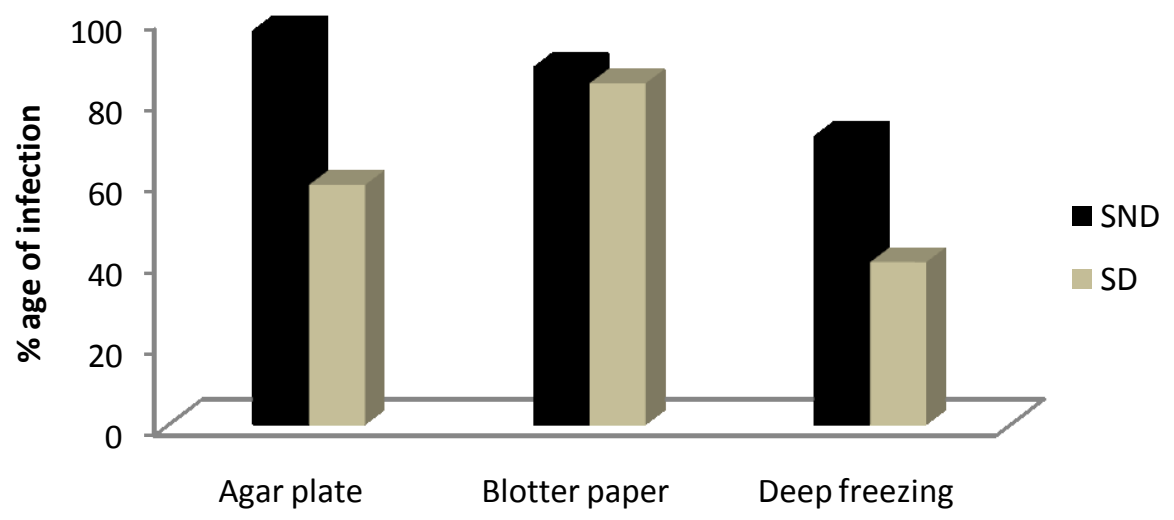

Fig.1. Percentage of fungal infection in sterilized and unsterilized seeds by all three methods 
Deep freezing method was found most suitable for the detection of Alternaria species. The average percent incidence and the range of occurrence of fungi in seed samples tested revealed that $A$. alternata, $A$. flavus, A. niger, Cercospora sp., F. oxysporum, P. egyptiacum and R. oryzae were most frequent and detected from all three methods. Few workers in Pakistan isolated fungi from sesame seeds by blotter paper method only $(4,32)$ and they recorded fungi like $A$. flavus, $A$. niger and $F$. oxysporum which is in confirmatory with present study. Surface disinfection of seeds with $2 \% \mathrm{NaOCl}$ reduced the incidence of Aspergillus spp. in blotter and deep freezing methods hence give similarity with the results of Bilgrami and Ghaffar (9). Species of Aspergillus, Penicillium and Rhizopus are reported to reduce the germination of seeds and damage the seeds in storage (10). A. flavus and A. niger were the predominant storage fungi of groundnut seeds (25), bottle gourd seeds (36), sunflower seeds (34) and soybean seeds (37). Rhizopus has been reported on ground nut seeds (30) and conifers (24). These species have been reported to reduce the germination of seed and damage the seeds in storage (10). F. oxysporum has been isolated in high frequencies from seeds of water melon (23), sponge gourd (33), and sunflower (1) causing wilting and seedling rot. A. alternata detected from sunflower cause characteristic leaf spot (8) and reduction in germination in wheat seeds (29).

The result of present study shows that seed samples are highly infected with pathogens which cause various diseases in sesame. On the other hand, these fungi are known to produce mycotoxins which are harmful for human health. A. flavus produces aflatoxin B1, B2, G1, G2 which are carcinogenic and mutagenic toxins (3). F. oxysporum produces Zearalenone $\alpha$ and $\beta$ causing haemorrhage and necrosis of bone marrow (11). $A$. niger attacks human skin and is a parasite of human ear. Thus there is a need for the control of these pathogens by employing various management techniques to ensure improvement of seed health which ultimately increase crop quality and human health.

\section{References}

[1] Abdullah, S. K. and K. A. Al-Mosawi. Fungi associated with seeds of sunflower (Helianthus annuus) cultivars grown in Iraq. 2010; Phytopathologia 57: 11-20.

[2] Alexopoules, C. J. and C. W. Mims. Introductory Mycology (3 $3^{\text {rd }}$ ed) John Wiley \& sons. Inc. 1979; New York, 632 Pp.

[3] Al-Hmoud, N., M. A. Ibrahim, Hiyam Al-Rousan and A. Alseyah. The Prevalence of Aflatoxinogenic Aspergillus parasiticus in Jordan. International Journal of Microbiology. 2012; doi:10.1155/2012/675361.

[4] Altaf, N., S. A. Khan, M. Ahmed, R. Asghar, R. A. Ahmed, S. Shaheen, M. Zafar and M. Saqib. Seed borne Mycoflora of Sesame (Sesamum indicum L.) and their effect on germination and seedling. 2004; Pak. J. Biol. Sci., 7: 243-245.

[5] Anonymous. World Sesame situation, American Sesame Growers Association. 2008.

[6] Arifeen, M. An open http://www.thefinancialdaily.com/NewsSearchResult/NewsSearchDetail.aspx?NewsId=89195.

[7] Ashri, A. Sesame Breeding. In Janick J (eds) Plant Breeding Reviews, Volume 16, John Wiley \& Sons. Inc Publishers, Oxford, UK. 1998; pp 179-228.

[8] Bhutta A. R., M. H. R. Bhatti and I. Ahmed. Relationship of seed-borne fungi to field diseases of sunflower. Pak. J. Sci. Ind. Res. 1999; 42: 93-97.

[9] Bilgrami, Z. and A. Ghaffar. Detection of seed-borne mycoflora in Pinus gerardiana. 1993; Pak. J. Bot., 25(2):225-231

[10] Christensen, C. M. Loss of viability in storage microflora. Seed Sci. \& Technol. 1973; 1: 547-562.

[11] Desjardins, A. E., M. Busman, R. Proctor and R. J. Stessman. Wheat kernel black point and fumonisin contamination by Fusarium proliferatum (abstract). National Fusarium Head Blight Forum Proceedings. 2006; pp.115.

[12] Domsch, K. H., W. Gams and T. H. Anderson. Compendium of soil fungi. Vol. 1. Academic Press, N.Y. $1980 ; 859$ p.

[13] Ellis, M. B. Dematiaceous Hyphomycetes, Commonwealth Mycological Institute, Kew, Surrey, England. 1971; 608 p.

[14] Ellis, M. B. More Dematiaceous Hyphomycetes, Commonwealth Mycological Institute, Kew, Surrey, England. 1976 ; 507 p.

[15] FAO. Agricultural data. In "Agricultural Statistics databases". Organization of the United Nations, Rome, Italy. 2004; http://faostat.fao.org.

[16] Farhan, H. N., B. H. Abdullah and A. T. Hameed. The biological activity of bacterial vaccine of Pseudomonas putida 2 and Pseudomonas fluorescens 3 isolates to protect sesame crop (Sesamum indicum) from Fusarium fungi under field conditions. 2010; Agric. Biol. J. N. Am., 1: 803-811

[17] ISTA. International rules for seed testing. Rules Amendments. Seed Science and Technology. 2001;29(2): 1-27.

[18] Jalbani, M. $\quad$ E. Sesame seed exports require right image-building. http://www.pakissan.com/english/advisory/sesame.seed.shtml temporal expression of a w-6 fatty acid desaturate cDNA from sesame (Sesamum indicum L.) seeds. Plant. Sci. 2001; 161: 935-941.

[20] Kassim, M. Y. Seed-borne fungi of sorghum in Saudi Arabia. Pak. J. Bot. 1985; 17(2): 263-266 seeds. Niger. J. Hort. Soc. 2000; 4: 57-64.

[22] Mbah, M. C. and C. O. Akueshi. Some Physico- chemical changes induced by Aspergillus flavus and Aspergillus niger on Sesamum indicum and Sesamum radiatum. J. Sci. Agric. Food Technol. Environ. 2001; 1: 65-69.

[23] Mclaughlin, R. J. and R. D. Martyn. Identification and pathogenicity of Fusarium species isolated from surface disinfected watermelon seed. J. Seed Tech. 1982; 7: 97-107.

[24] Mittal, R. K. and B. S. P. Wang. Effects of some seed-borne fungi on Picea glauca and Pinus strobes seeds. Eur. J. Forest Pathol. 1993; 23: 138-146.

[25] Mukherjee, P. S., S. K Nandi and B. Nandi. Deterioratiue. Changes in groundnut seeds in storage. Journal of Mycopathological Research. 1992; 30(2): 113-119.

[26] Panchal, V. H. and D. A. Dhale. Isolation of seed-borne fungi of Sorghum (Sorghum vulgare Pers.). J. Phytol. 2011; 3: 45-48.

[27] Pastorello, A. E., E. Varin, L. Farioli, V. Pravettoni, C. Ortolani, C. Trambaioli, D. Fortunato, M. G. Giuffrida, F. Rivolta, A. Robino, A. M. Calamari, L. Lacava and A. Conti. The major allergen of sesame seeds (Sesame indicum) is a $2 \mathrm{~S}$ albumin. J. Chromatogr. B: Biomed. Sci. App. 2001; 756:85-93. 
[28] Perveen, S. and A. Ghaffar. Seedborne mycoflora of Tomato. Pak. J. Bot. 1995; 27(1): 201-208.

[29] Rajput, M. A., M. A. Pathan, A. M. Lodhi, G. S. Shah and K. A. Khanzada. Studies on seed-borne fungi of wheat in sindh province and their effect on seed germination. Pak. J. Bot. 2005;37:181-185

[30] Rasheed, S., S. Dawar, A. Ghaffar and S. S. Shaukat. Seed borne mycoflora of groundnut. Pak. J. Bot. 2004;36: 199-202

[31] Rathod, L. R., M. D. Jadhav, S. K. Mane, S. M. Muley and P. S. Deshmukh. Seed borne mycoflora of legume seeds. International Journal of Advanced Biotechnology and Research. 2012;3: 530-532

[32] Shakir, A. S. and M. Ansar. Fungi associated with sesame seed. Pak. J. Agri. Sci. 1992;29: 319-320.

[33] Shakir, A. S., J. H. Mirza, S. T. Sahi and F. Ahmad. Detection of seed-borne fungi associated with sponge gourd \{Luffa cylindrica (L.) Roem.\}, their location in different seed components and their control. Pak. J. Phytopathol. 1995;7: 140-144.

[34] Sharfun-Nahar, M. Mushtaq and M. H. Hashmi. Seed-borne mycoflora of sunflower (Helianthus annuus L.). Pak. J. Bot. 2005;37:451-457.

[35] Shyu, Y. S. and L. S. Hwang. Antioxidative activity of the crude extract of lignan glycosides from unroasted Burma black sesame meal. Food Res. Int. 2002;35:357-365.

[36] Sultana, N. and A. Ghaffar. Seed borne fungi associated with bottle gourd (lagenaria siceraria (MOL.) STANDL. Pak. J. Bot. 2009;41: 435-442.

[37] Tariq, M., S. Dawar, M. Abid and S. S. Shaukat. Seed-borne mycoflora of soyabean. Int J.Biol. Biotech. 2005;2: 711-7113.

[38] Thom, C. and K. B. Raper. Manual of Aspergilli. Williams Company, Baltimore, USA. 1945;373 p. 